\title{
PEDAGOGY
}

\section{Развитие преподавания английского языка в университетах Украины в контексте евроинтеграции}

\author{
А. Г. Андрощук \\ Киевский национальный университет имени Тараса Шевченка \\ Corresponding author. E-mail: lang1@ukr.net
}

Paper received 20.10.19; Accepted for publication 05.11.19.

\section{https://doi.org/10.31174/SEND-PP2019-208VII85-01}

Аннотация. В статье рассмотрены состояние и тенденции в преподавании английского языка в Европейском пространстве высшего образования и университетах Украины за последние годы. Определены основные новации, основанные на европейском опыте, раскрыта сущность государственной политики по развитию английского языка в сфере высшего образования, Концепции развития английского языка в университетах.

Ключевые слова: английский язык, европейские стандарты высшего образования, уровень владения английским, университет, единый вступительный экзамен, профессиональный стандарт учителя, методы обучения, системы оценивания.

Введение. "Владение английским языком признано базовым жизненным умением XXI века наравне с умением пользоваться компьютером, сейчас это уже не отдельная специализация. Английский дает людям возможность работать со значительно более широким разнообразием информации, знакомиться с большим количеством взглядов, чем это можно было бы сделать только на родном языке"[1, с.13] подчеркивает директор Британского Совета (англ. British Council) в Украине Саймон Уильямс в своем предисловии к объемному и интенсивному исследованию "Тhe internationalisation of Ukrainian universities: the English language dimension" ("Интернационализация украинских университетов в разрезе английского языка»), проведенном от имени Британского Совета и Министерства образования и науки Украины в 2014-16 гг., о роли и статусе английского языка в 15 высших учебных заведениях Украины.

В то же время, как отмечает Министр образования и науки (МОН) Украины, к.п.н. Л. Гриневич, «исследования показывают, что экономическое развитие стран очень зависит от знания гражданами английского языка. Растет важность знания английского языка всеми специалистами. И сегодня, когда мы смотрим на Украину, то среди не англоязычных стран Европы, которых 32, мы по уровню знания английского языка находимся на 28 месте.... Уровень, с которым в вузы попадают поступающие очень разный. Это вредит как студентам с низким уровнем, которые не успевают по программе, не могут нормально ее усваивать, так и сильным студентам, страдающим от политики «ориентации на более слабого» [2].

Установлено, что чем выше уровень английского языка у населения, тем богаче страна. Поэтому на вершине рейтинга знания находятся страны с большим валовым национальным доходом (ВНД), а внизу - с маленьким. В Украине скромный ВНД и такой же уровень английского языка. Среди 88 стран, где его изучают в школах, Украина на 43-м месте. Согласно исследованию Kantar TNS Online Track 70\% украинцев изучали английский язык, но только $35 \%$ заявили, что могут поддержать разговор или понять новости по радио или телевидению на английском. Опрошенные в среднем оценили свои знания языка на 3,7 из возможных 10 баллов. При этом 90\% признали, что для личного развития они бы изучали английский [3]. Иностранный язык - один из основных механизмов реализации интеграционных процессов, мобильности студентов, ученых и специалистов, особенно учитывая Болонские договоренности.

Учитывая тенденции, происходящие в Европейском пространстве высшего образования целесообразно более подробно изучить влияние процессов евроинтеграции и глобализации на преподавание английского языка и ввести лучшие методики и практики преподавания английского языка в систему высшего образования Украины.

Обзор публикаций по теме исследования. Изучением новейших технологий, методов и приемов в преподавании иностранных языков и английского в частности, занимаются многие отечественные и зарубежные ученые, а именно: Анисимова А., Бех П., Вишневский А., Заборовский В., Мерзликина И., Крючков Г., Пуховская Л., Сенченко В., Соловьева Н., Степаненко С., Тарнопольский А., Штульман Е., Бернс М., Болайто Г., Вест Г., Штерн Г., Боткин Д. и др.

Проблемы обеспечения развития, оценки, измерения и сравнения и контроля качества в Европейском пространстве высшего образования исследуют Аношков Т., Драч И., Калашникова С., Луговой В., Мосьпан Н., Поликарпова Ю., Оржель А., Сысоева С., Слюсаренко А., Таланова Ж., Ярошенко А. и другие ученые.

Целью статьи является анализ, тенденций и инновационных изменений, осуществляемых в Европейском пространстве высшего образования в процессе преподавания английского языка в системе высшего образования Украины в контексте евроинтеграции, в частности, содержания Концепции развития английского языка в университетах.

Состояние и тенденции в преподавании английского языка в Европейском пространстве высшего образования и университетах Украины. Глобализация мира и развитие единой Европы превращают интеграцию национального образования в европейское и инновационное мировое образовательное пространство в обязательное условие бытия украинского государ- 
ства. Проблемным моментом на пути интеграции является непоследовательность образовательной политики, поэтому этот процесс имеет прерывный характер. Новый этап, начавшийся с 2014 г.. после социальнополитического кризиса, военной агрессии России и подписания Соглашения об ассоциации между Украиной и ЕС (2014), ознаменовался интенсификацией европейского вектора развития Украины и синхронизацией измерений украинского образования с европейскими характеристиками. Продолжается поступательное движение украинского образования в направлении его трансформации на компетентно основанную.

Украина признает высшее образование как двигатель социальной трансформации, а английский язык как ключевую компетенцию в условиях интеграции и глобализации экономики, инструмент международного общения, средство присоединения к европейскому образовательному, научному и профессиональному пространству, условия эффективной интеграции и фактора экономического роста страны. Государство подтвердило свой европейский выбор и внешнеполитический вектор (Конституция Украины, ст. 102), приверженность европейской интеграции и глобализации (Соглашение об ассоциации между Украиной и ЕС, членство в Европейском пространстве высшего образования и Европейском научном пространстве, других международных институтах, партнерстве и сотрудничестве ). Стоит отметить, что инструменты, разработанные в рамках Совета Европы, в частности, Общеевропейская система ссылок на языки: обучение, преподавание, оценка (CEFR), сыграли решающую роль в преподавании так называемых «иностранных» языков, способствуя методологическим инновациям и новым подходам к разработке программ обучения, особенно развития коммуникативного подхода. Они способствовали новому подходу к распространению этих методов обучения таким образом, который потенциально более благоприятный для оперативного усвоения неизвестных языков. Поэтому, определяя языковые потребности, они смогли точно определить знания и ноу-хау, необходимые для достижения этого «порога общения». CEFR организует владения языком на шести уровнях, от A1 до C2, которые могут быть перегруппированы в три широких уровня: базовый пользователь, независимый пользователь и опытный пользователь, и которые могут быть дополнительно подразделены в соответствии с потребностями местного контекста. Уровни определяются с помощью дескрипторов can-do. Указанные уровни не возникли внезапно в 2001 году, а являются результатом двадцатилетнего исследования. Этот инструмент создан, чтобы обеспечить прозрачную, слаженную и всеобъемлющую основу разработки языковых программ и пособий по учебным программам, учебно-методических материалов и оценки уровня владения иностранным языком. CEFR используется не только в Европе, но и на других континентах и доступна на 40 языках [4]. Важность английского языка для доступа и расширения образовательных и профессиональных возможностей человека признается Украиной и отражена в ряде национальных стратегий и инициатив, где владение английским языком является центральным, включая: признание необходимости обеспечить конкурентоспособность украинских уче- ных и выпускников на национальном и международном уровнях; стремление к интернационализации высшего образования; программы академической и образовательной интеграции в рамках ЕС; обязательность изучения английского языка в начальном и среднем образовании; изучение и применение опыта проекта «Английский для университетов», который поддержал внедрение и распространение в университетах английского языка профессионального направления и преподавания профессиональных дисциплин на английском языке; принятие Национальной рамки учебной программы по английскому языку профессионального направления для использования в университетах Украины; распространение Общеевропейских рекомендаций языкового образования (CEFR) для определения уровня владения английским языком в Украине; определение изучения иностранных языков, в частности английского, приоритетом внутренней политики в стратегических документах Украины.

Так, Стратегия устойчивого развития "Украина2020" в рамках «Программы популяризации Украины в мире и продвижения интересов Украины в мировом информационном пространстве» предусматривает усиление институциональной способности для осуществления международных стратегических коммуникаций; увеличение и оптимизацию присутствия Украины на международных мероприятиях и площадках; присутствия в международной академической, культурной и общественной среде. Одним из стратегических индикаторов реализации Стратегии является «75\% выпускников общеобразовательных учебных заведений будут владеть по меньшей мере двумя иностранными языками, подтверждаться международными сертификатами» [5]; присоединения к GoGlobal и принятия Национальной программы изучения и популяризации иностранных языков «Украина speaking»; проведения года английского языка в Украине (2016) и др.

В то же время, в общем, как показывают результаты исследования, уровень владения английским языком в Украине является низким. Согласно рейтингу English Proficiency Index (EPI) 16 в 2016 году Украина заняла 41 место среди 72 стран, которые входили в исследование. Этот результат является худшим показателя 2015 года, когда Украина была на 34 месте, а в рейтинге 26 европейских стран в 2016 году Украина среди последних [1, с.33]. МОН Украины установило требования к владению английским языком для всех университетских преподавателей на уровне В2 по шкале Общеевропейских рекомендаций языкового образования, однако не определило уровень владения языком для университетских преподавателей английского языка. Между тем МОН Украины отметило, что уровень учителей английского языка при окончании университета является соотносительным шкале Общеевропейских рекомендаций языкового образования. Разговорная речь является слабым умением преподавателей одновременно студенты высоко оценивают занятия с разговорным практикой. Все больше профессиональных дисциплин начинают преподавать на английском языке, поэтому существует соответствующая потребность повышать уровень английского языка как студентам, так и преподавателям. Поэтому ограниченное владение английским преподавателей языка/преподавателей ан- 
глийского языка профессионального направления станет более заметным, чем сейчас [1, с.43]. В исследовании по английскому языку профессионального направления эксперты пришли к выводу: причина разрыва между потребностями целевой ситуации (рынком труда) и современным уровнем владения языком лежит в отсутствии общепринятых критериев содержания, методики, построения курса, оценки и результатов обучения, соответствующих международным стандартам. В течение последних 13 лет преподавания английского языка профессионального направления не расширялось и не реформировалось, а преподавание специальных дисциплин на английском языке не стало массовым [1, c.113].

Выработка государственной политики по развитию английского языка в сфере высшего образования Украины. Задачи государственной политики по развитию английского языка в высшем образовании в Украине, в соответствии с целью, включают: совершенствование законодательства для поддержки развития английского языка в сфере высшего образования; установление требований к уровню владения английским языком на различных этапах образовательного континуума; содействие трансформации статуса английского языка. С учетом изложенного МОН Украины вместе с Британским Советом в Украине разработало и одобрило на заседании Коллегии «Концепцию развития английского языка в университетах» [5].

Рассмотрим ее основные составляющие. Документ предусматривает организацию языковых курсов и интенсивов, владение английским языком на уровне не менее В1 станет обязательным условием для вступления, В2 - для выпуска, часть профильных дисциплин предлагают сделать англоязычными и проводить регулярные «скрининги знаний», в частности, ввести обязательное Внешнее независимое оценивание (BНО) по иностранному языку после бакалавриата. Поэтому решение только одно - обеспечить вход на уровне В1 всех студентов в начале обучения. Цель - к 2023 году все студенты должны овладеть языком на соответствующем уровне. Для этого концепция предполагает, что к 2023 году уровень владения английским на уровне В1 будет обязательным при поступлении на бакалавра. Это предполагает: прохождение обязательного «скринингового» теста по английскому языку всеми абитуриентами (например, ВНО или стандартизированные иностранные тесты) с целью установления уровня владения языком. Если уровень поступающего ниже В1, это не лишает его права участвовать в конкурсе на поступление в учреждения высшего образования (УВО) в обычном режиме. Однако такие абитуриенты к началу учебного года (до 1 сентября или до 1 октября) должны пройти языковой интенсив для достижения уровня В1. Обеспечивается равный доступ к этому языкового интенсива для достижения уровня В1 (очный, дистанционный). Через стандарты высшей школы будет прописано требование, студент бакалавриата обязательно, независимо от специальности, должен усвоить иностранный язык на уровне В1 +, если он хочет получить диплом. Для старших уровней магистры и доктора философии с академическим компонентом - обязательным будет уровень В2. Для поощрения университетов к преподаванию и студентов к изучению английского языка во время бакалавриата концепция предусматривает увеличение часов и изменение содержания языковых дисциплин. Планируется, что в дальнейшем широко использовать экзамены для подтверждения уровня владения английского языка на уровне В2. Если конкретизировать, то это предполагает:

В краткосрочной_перспективе распространить Единый вступительный экзамен (ЕВЭ) - то есть "ВНО в магистратуру" по иностранному языку - на все магистерские специальности для подтверждения уровня В2. Для влияния на содержание английского языка и компетенции, которые преподаются на уровне бакалавра, будут разработаны подробные спецификации ЕВЭ и определена конкретная программа и структура содержания экзамена. Цель этих изменений - стимулирование развития полного спектра языковой компетентности и влияние на изучение английского языка во время бакалаврата. В среднесрочной перспективе (5-7 лет) планируется заменить экзамен ЕВЭ обязательным стандартизированным единственным выходным (квалификационным) экзаменом по английскому языку для всех студентов бакалаврата.

Для создания соответствующих стимулов для университетов и студентов к поддержке уровня английского языка на уровне В2 у студентов во время магистратуры, Концепция предлагает: ввести оценивание английского языка как компонента единого государственного квалификационного экзамена (ЕГКЭ) для большинства специальностей, в режиме «сдал/не сдал»; для специальностей, для которых не предусмотрен ЕГКЭ, рекомендовано вузам проводить оценку владения английским языком во время аттестации магистров. По данным Украинского центра оценивания качества образования (УЦОКО), в 2019 году внешнее независимое оценивание (BНО) по английскому языку (порог "сдал/не сдал") преодолели 87,3\% абитуриентов. Порог "сдал/не сдал" - это минимальное количество тестовых баллов, которое должен набрать участник ВНО, чтобы получить оценку в шкале 100-200 баллов. Это дает поступающему право участвовать в конкурсном отборе в УВО [6].

Концепция рекомендует включить УВО оценивание качества преподавания английского языка отдельным пунктом в своей системе внутреннего обеспечения качества образования заведения, а Национальное агентство по обеспечению качества высшего образования - сделать этот критерий обязательной частью внешней системы обеспечения качества. Документ предусматривает также, что поощряется развитие бесплатных онлайн курсов для самостоятельного изучения учащимися и студентами английского языка. В этом году школьники, студенты, учителя и преподаватели более чем тысячи учебных заведений Украины присоединились к изучению английского на бесплатной платформе Lingva.Skills, размещенной на сайте $\mathrm{MOH}$ Украины. Такой формат должен стать дополнением к регулярному изучению языка в школе и университете, а также для различных уровней учеников. Эти курсы помогут студентам, желающим поступить на бакалаврские, магистерские и докторские программы достичь определенного уровня английского языка. 
Ключевое - стимулирование преподавания УВО профессиональных дисциплин на английском языке. Для того, чтобы поддерживать уровень владения языком, нужна постоянная практика. Университет - единственное место, где студент благодаря именно таким программам может погрузиться в англоязычную среду. Вместе с Британским Советом и другими партнерами $\mathrm{MOH}$ Украины разработаны также рекомендации для УВО по преподаванию английского языка в Украине и преподавания профессиональных дисциплин на ан-

Выводы. Обеспечение системы высшего образования интегрированной в Европейское пространство высшего образования (ЕПВО) и Европейское исследовательское пространство является одной из целей реформирования системы высшего образования в Украине. Формирование и совершенствование нормативнов Украине, в частности обеспечение его качества в соответствии с европейскими стандартами является одним из приоритетов деятельности как высших органов власти в сфере образования, так и самих высших учебных заведений. Стратегией реформирования высшего образования (п.3.2.) Предусмотрено создание системы обеспечения и постоянного улучшения качества высшего образования, соответствующего рекомендациям и стандартам Европейского пространства высшего образования, учитывает лучшие мировые практики и выступает главной технологией достижения соответствия образовательной системы требованиям и потребностям общества и личности. Нормативно-правовое регулироглийском языке. правового регулирования сферы высшего образования

вание сферы высшего образования в Украине - это совокупность правовых средств, с помощью которых осуществляется правовое регулирование общественных отношений в сфере образования. Правовые нормы, осуществляющих регулирование общественных отношений формируют систему с характерной для нее иерархией уровней связей и структурой. Формирование с учетом европейских стандартов и международного опыта прогрессивной нормативно-правовой базы, в первую очередь, по обеспечению качества образования является одним из основных факторов, обеспечивающих реализацию прав человека на качественное образование и одним из основных факторов подготовки квалифицированного специалиста. Английский язык признается ключевой компетентностью современного человека, ключевым инструментом международного общения в академической и профессиональной жизни и для развития страны в целом, средством доступа к знаниям, условием эффективной мировой интеграции и фактором экономического роста страны. Задача государственной политики по развитию английского языка в высшем образовании в Украине, изложенной, в частности, в Концепции развития английского языка в университетах, в соответствии с целью включают: совершенствование законодательства для поддержки развития английского языка в сфере высшего образования; установление требований к уровню владения английским языком на различных этапах образовательного континуума; содействие трансформации статуса английского языка.

\section{ЛИТЕРАТУРА}

1. The internationalisation of Ukrainian universities: the English language dimension./ Rod Bolitho and Richard West. URL: http://www.britishcouncil.org.ua/sites/default/files/2017-1004_ukraine_-_report_h5_en.pdf

2. МОН створило Концепцію розвитку англійської мови в університетах: рівень В1- обовязкова умова вступу, В2 випуску, викладання профільних дисциплін іноземною та «мовні скринінги». URL: https://mon.gov.ua/ua/news/monstvorilo-koncepciyu-rozvitku-anglijskoyi-v-universitetah-udodatku-riven-v1-obovyazkova-umova-vstupu-v2-vipuskuvikladannya-profilnih-disciplin-inozemnoyu-ta-movniskriningi

3. Віталій Андронік Англійська стане обов'язковою: Міносвіти готує серйозні зміни. URL: https://ukr.segodnya.ua/ukraine/angliyskiy-stanetobyazatelnym-chto-gotovyat-v-minobrazovaniya1302902.html

4. The CEFR Levels. URL: https://www.coe.int/en/web/commoneuropean-framework-reference-languages/level-descriptions

5. Указ Президента України Про Стратегію сталого розвитку "Україна 2020" - URL: https://zakon5.rada.gov.ua/laws/show/5/2015

6. Цьогоріч 3 HО 3 англійської мови не склали $12,7 \%$ абітурієнтів. URL: https://espreso.tv/news/2019/06/19/cogorich_zno_z_angliyskoy i_movy_ne_sklaly_12_7_abituriyentiv

7. Національна доповідь про стан і перспективи розвитку освіти в Україні/Нац. акад. пед. наук України; [редкол.: В. Г. Кремень (голова), В. І. Луговий (заст. голови), А. М. Гуржій (заст. голови), О. Я. Савченко (заст. голови)] ; за заг. ред. В. Г. Кременя. - Київ: Педагогічна думка, 2016. — 448 с. - Бібліогр.: с. 21. - (До 25-річчя незалежності України).

\section{REFERENCES}

2. https://mon.gov.ua/ua/news/mon-stvorilo-koncepciyu-rozvitkuanglijskoyi-v-universitetah-u-dodatku-riven-v1-obovyazkovaumova-vstupu-v2-vipusku-vikladannya-profilnih-disciplininozemnoyu-ta-movni-skriningi

3. https://ukr.segodnya.ua/ukraine/angliyskiy-stanetobyazatelnym-chto-gotovyat-v-minobrazovaniya1302902.html

5. https://zakon5.rada.gov.ua/laws/show/5/2015

6. https://espreso.tv/news/2019/06/19/cogorich_zno_z_angliyskoyi movy_ne_sklaly_12_7_abituriyentiv

7. National report on the state and prospects of educational development in Ukraine/ National Academy of Pedagogical Sciences of Ukraine.

\section{Development of teaching English in the context of European integration}

\section{A. Androshchuk}

The article deals with the state and tendencies of teaching English in the European Higher Education Area and universities of Ukraine in recent years. The main innovations based on the European experience are identified, the essence of the state policy on the development of English language in the field of higher education, the Concept of English language development in universities is revealed.

Keywords: English, European Higher Education Standards, English Proficiency, University, Uniform Entrance Exam, Professional Teacher Standard, Teaching Methods, Assessment Systems. 